\title{
Dual mode controller based boost converter employing soft switching techniques
}

\author{
J. Velmurugan ${ }^{1}$, R. M. Sekar ${ }^{1}$, Jojina anna varghese ${ }^{2}$ \\ ${ }^{1}$ Dept. Of EEE, Associate Professor, PSNACET, Dindigul, Tamilnadu, India \\ ${ }^{2}$ Dept. Of EEE, PSNACET, Dindigul, Tamilnadu, India
}

\section{Email address:}

vel_76@yahoo.co.in(J.Velmurugan),jo.sanjana@gmail.com(J. a.varghese)

\section{To cite this article:}

J. Velmurugan, R. M. Sekar, Jojina anna varghese. Dual Mode Controller Based Boost Converter Employing Soft Switching Techniques. International Journal of Energy and Power Engineering. Vol. 2, No. 3, 2013, pp. 90-96. doi: 10.11648/j.ijepe.20130203.11

\begin{abstract}
This paper proposes a dual mode used to control a single phase soft switching boost power factor correction Converter (PFC) developed with a new active snubber circuit. The soft switched boost power factor correction converter has merits of less voltage and current stresses, improved efficiency and reduced switching losses. Thus the cost and complexity of the converter is reduced. The dual mode controller combines both continuous conduction mode (CCM) and critical conduction mode (CRM). The simulation results declare high efficiency and optimum power factor for wide range of varying loads.
\end{abstract}

Keywords: Power Factor Correction(PFC), Soft Switching(SS), Zero-Current Switching(ZCS), Zero-Voltage Switching(ZVS), Zero-Current Transition(ZCT), Zero-Voltage Transition(ZVT)

\section{Introduction}

Conventional ac-dc converters are also called rectifiers. They are developed using diodes and thyristors to provide controlled and uncontrolled dc power with unidirectional and bidirectional power flow.AC-DC converters have demerits such as poor power quality due to injected current harmonics, voltage distortions, poor power factor at input ac mains, slowly varying rippled dc output at load end and low efficiency. These converters have high switching frequency which results in high switching losses and increased electromagnetic interference[1]. To reduce the input current harmonics and to improve the power factor, a power factor correction converter is used with soft switching techniques. While converting $\mathrm{AC}$ to $\mathrm{DC}$, the conventional diode rectifiers always produce large amounts of harmonic current. PFC can reduce the harmonics in the line current, increase the efficiency and capacity of power system and reduce customer's utility bill.

The boost topology is mainly used to implement the power factor correction converter. It can produce a high output voltage from a low input voltage. There are two main methods of power factor correction converter: Active method and Passive method[2]. The passive method in which an inductor is added at the dc side of the diode bridge is the most commonly used one.An active snubber circuit is added to the output stage of the boost converter to reduce the recovery losses and to provide the soft switching conditions to the switches[4]. Hard switching results in high switching frequency operation due to which switching losses increases. Whereas soft switching results in less switching losses, high power density, high reliability and efficiency. The snubber circuit provides ZVT turn ON and ZCT turn OFF together for the main switch and ZCS turn ON and turn OFF for auxiliary switch without increasing the cost and complexity of the converter. Thus there will be no voltage stresses or current stresses on the main switch. But there is a current stress on the auxiliary switch which can be decreased by diverting a part of the current to the output side with a coupling inductance[5]. A dual mode controller can be used instead of PWM. The dual mode control scheme combines both continuous conduction mode (CCM) and critical conduction mode (CRM) modes. It provides a simple control and high output power. It requires no additional space and cost. This scheme is used in PC applications and can be easily implemented in ICs.

\section{Brief Description of PFC Converter}

The proposed paper implements a single-phase soft-switching power factor correction converter which is developed with an active snubber cell and dual mode 
controller. The aim is to achieve high efficiency and improve the power factor in a light-load condition. The bock diagram of pfc implementing an active snubber cell is shown in "Fig. 1".

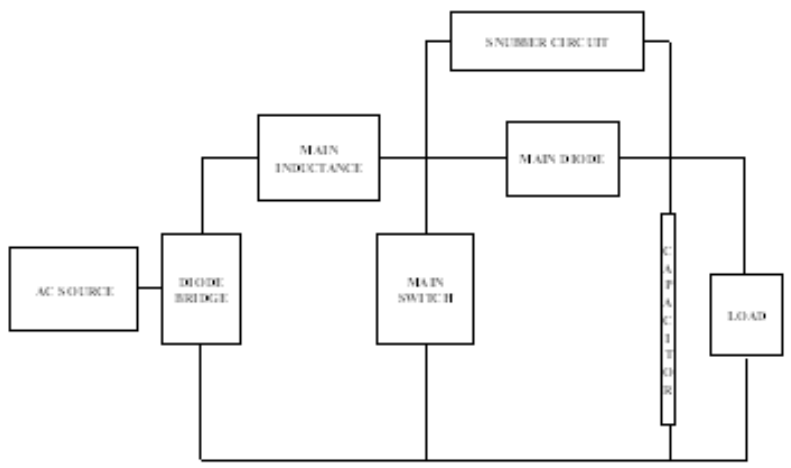

Figure 1. Block diagram of PFC converter

A low power factor reduces the power available from the utility grid while a high harmonic distortion of the line current causes EMI problems and cross interferences. So it is necessary to use a PFC. The three basic power converters used are buck, boost and buck-boost. The buck converter has discontinuous input current and would lose control when input voltage is lower than the output voltage. The boost converter and buck-boost (fly back) converter are both suitable for PFC. The buck-boost converter can achieve average input line current but it has higher voltage and current stress, so it is usually used for low power applications. The boost converter is the most suitable for use in implementing PFC [6]. It is widely used for its smaller EMI filter and low voltage stress. The boost inductor is connected in series with the line input terminal, therefore the inductor will achieve smaller current ripple.

The power factor correction converter has two main topologies:-

i. Active method

ii. Passive method

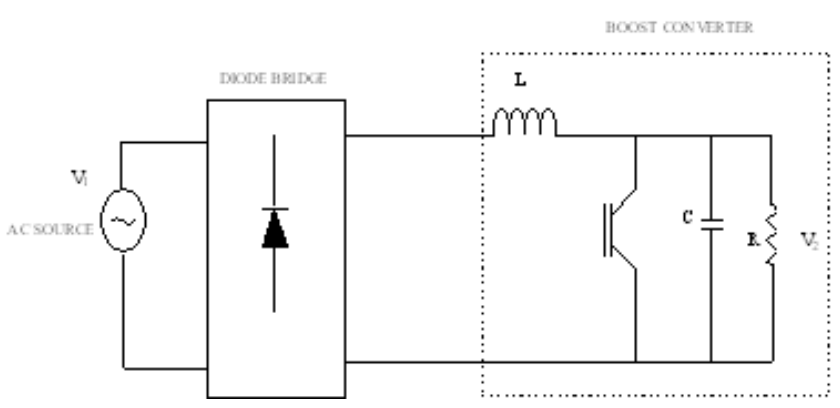

Figure 2. Passive topology of PFC

The passive method of PFC is shown in "Fig. 2". where the inductor is placed at the dc side of the bridge rectifier. An ideal PFC should emulate a resistor on the supply side while maintaining a fairly regulated output voltage. The output of the diode bridge is connected to a boost converter. The main aim of the PFC is to eliminate the harmonics[7]. The dc side consists of second and fourth harmonics. Whereas the ac side contains third harmonics. To eliminate the third harmonics, firstly the second and fourth harmonics at the dc side must be eliminated. So a snubber circuit is used to provide the soft switching techniques so as to reduce the harmonics. This increases the efficiency and capacity of the power systems. The output capacitor absorbs the input power pulsation. This capacitor is also an efficient energy storage element.

\section{Power Factor Correction Converter Using SS Techniques}

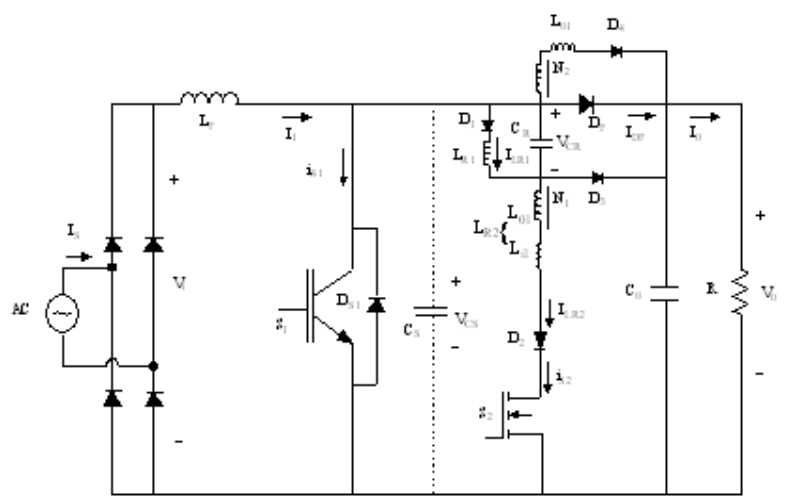

Figure 3. Circuit scheme for PFC converter implementing snubber circuit

The snubber cell provides the soft switching (SS) conditions to the switches in a PFC. The circuit diagram of a PFC implementing an active snubber cell is shown in "Fig. 3". The main power circuit consists of a diode bridge, main boost switch $\mathrm{S}_{1}$, boost inductor $\mathrm{L}_{\mathrm{F}}$, the boost main diode $\mathrm{D}_{\mathrm{F}}, \mathrm{C}_{\mathrm{S}}$ the sum of the parasitic capacitors of the main switch and the main diode, and the output capacitor $\mathrm{C}_{0}$. The auxiliary/snubber circuit consists of the snubber inductances $\mathrm{L}_{\mathrm{R} 1}$ and $\mathrm{L}_{\mathrm{R} 2}$, the coupling inductance $\mathrm{L}_{01}$, snubber capacitor $C_{R}$, auxiliary switch $S_{2}$ and auxiliary diodes $D_{1}, D_{2}, D_{3}$ and $D_{4}$. $V i$ is the input dc voltage, $v_{0}$ is the output voltage. The output is the R-load. The diode bridge rectifies the variable input $\mathrm{AC}$ source voltage $(50 \mathrm{~Hz})$ into an uncontrolled DC voltage. The boost converter converts the uncontrolled dc into a controlled dc voltage. The output capacitor $\mathrm{C}_{0}$ filters the second harmonic current and prevents its appearing at the load. The main inductor $\mathrm{L}_{\mathrm{F}}$ is connected serially to the main switch to slow down the rise in current when the switch is turned $\mathrm{ON} . \mathrm{D}_{2}$ is placed serially to the auxiliary switch to prevent extra current stress for the main switch. The main switch $S_{1}$ is turned ON by ZVT and turned OFF by ZCT. The auxiliary switch $\mathrm{S}_{2}$ is turned ON and OFF with ZCS. The snubber cell provides the soft switching techniques and it can be achieved by satisfying following conditions[6].

\subsection{ZVT Turn ON of the Main Switch}

Auxiliary switch is turned ON before turning ON the 
main switch. The parasitic capacitor of the main switch should be discharged completely, thus initiating a resonant process [9]-[11]. Thus the main switch's ant parallel diode is turned ON. The resonant process creates ZVS conditions for the main switch to turn $\mathrm{ON}$.

\subsection{ZCT Turn OFF of the Main Switch}

The auxiliary switch is turned $\mathrm{ON}$ before the main switch is to be turned OFF and diverts the current away from the main switch. A resonant process is initiated and it provides the ZCS condition for the main switch to turn OFF. The auxiliary circuit is ON only for a short duration of time and is deactivated quickly after the main switch is turned $\mathrm{OFF}[12]$.

\subsection{ZCS Turn ON of the Auxiliary Switch}

The auxiliary circuit is activated only during the main switch transitions and so it is only for a small time during the switching cycle. This limits the auxiliary circuit losses[13]. The auxiliary switch is turned ON with ZCS because coupling inductance limits the current rise speed.

\subsection{ZCS Turn OFF of the Auxiliary Switch}

The auxiliary switch is turned OFF as soon as the main switch transitions are obtained. When the control signal of the auxiliary switch is cut off. Thus the auxiliary switch is turned OFF with ZCS[14]-[16].

\section{PFC Dual Mode Controller}

A dual mode controller is used to control the PFC at light load conditions. The PWM controller works at continuous conduction mode(CCM). But it provides recovery losses on the boost diode. At critical conduction mode(CRM), the reverse recovery losses are eliminated, thus reducing switching losses to obtain a high efficiency. But at CRM there are demerit such as high conduction losses due to which the efficiency becomes poor.

A diode rectifier effects the ac/dc conversion while the controller operates the switch in such a way to properly shape the input current $i_{g}$ according to its reference. The dual mode controller combines both CCM and CRM. It solves both the problems of recovery losses and conduction losses. It provide higher output power, higher efficiency in a light load condition and is fit for PC power application. The controller is composed of a CCM IC and a zero current detection(ZCD) circuit [8]. When the signal of ZCD changes from a negative to a positive level, it causes a zero hysteresis comparator and when ZCD changes from a positive to negative level, the output signal of a zero hysteresis comparator is maintained at zero level. The control objective is to force the input current to follow the current reference. As shown in the "Fig. 4" three signals are required to implement the control. These are the rectified input voltage, $V_{\text {in }}$, the inductor current $I_{\text {in }}$ and the $d c$ capacitor voltage $\mathrm{V}_{\mathrm{O}}$.
The controller has two main tasks:-

a) Provides the output a same shape as that of the input voltage. This task gives a unity power factor.

b) Voltage regulation regulates the output voltage keeping the output voltage equal to $400 \mathrm{~V}$ which is higher than the input voltage.

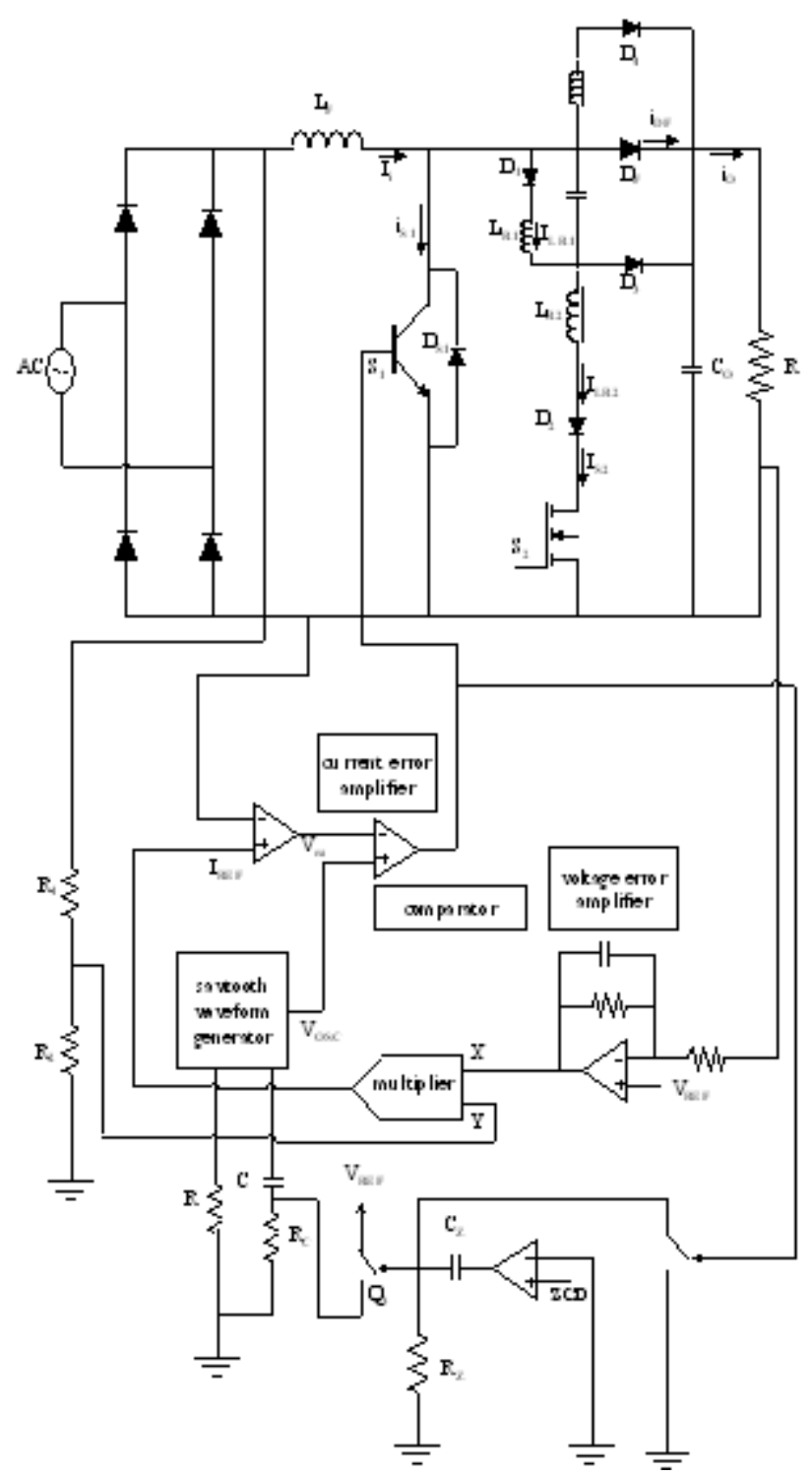

Figure 4. Dual mode controller

\section{Experimental Results and Discussions}

A prototype of $300 \mathrm{~W}$ and $100 \mathrm{kHz}$ PFC converter is used. The PFC converter is obtained by adding ZVT-ZCT PWM active snubber circuit to the boost converter which is fed by universal input ac line. $200 \mathrm{~V}$ ac is applied to the input of the converter. This voltage rectified to dc voltage the boost converter. This boost converter has the main switch. An active snubber circuit is used tp provide SS technique to the main switch. The auxiliary switch is included in the snubber circuit. The main switch operates at $100 \mathrm{kHz}$. The 
auxiliary switch operates twice in one switching cycle of the main switch; so the auxiliary switch is operated at $200 \mathrm{kHz}$. The main switch has ZVT turn ON and ZCT turn OFF whereas auxiliary switch has ZCS turn ON and turn OFF.

\subsection{Simulation Results}
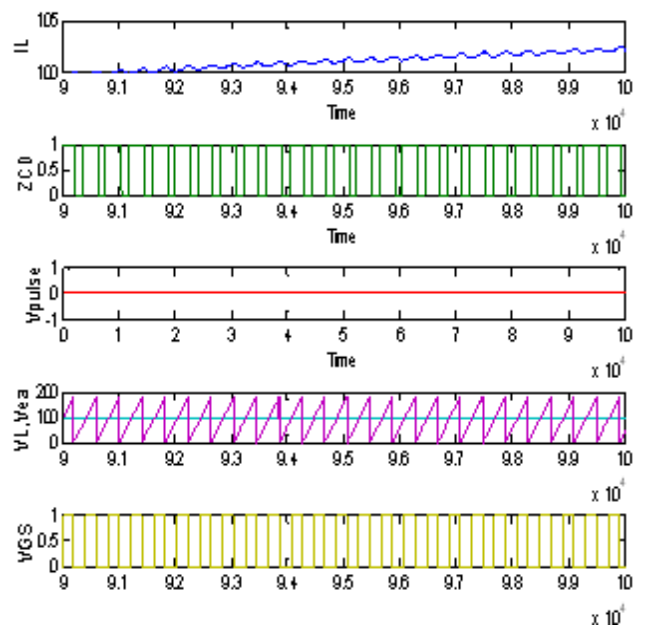

(a)
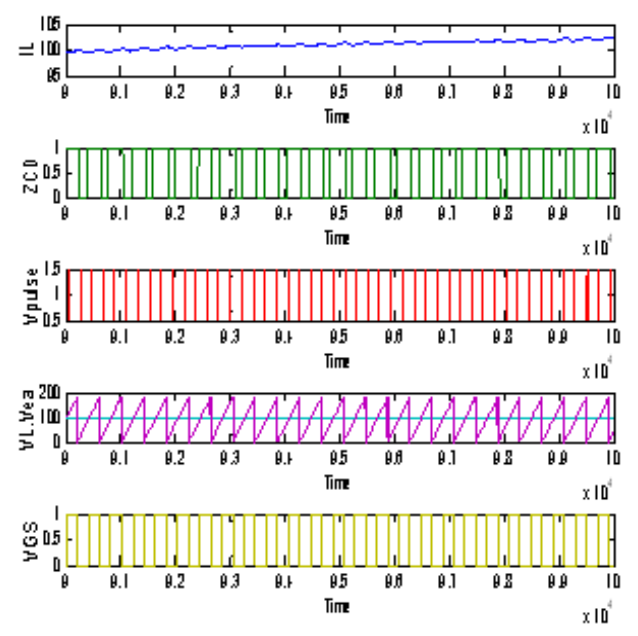

(b)

Figure 5. Waveforms of (a) output of the proposed controller at heavy-load condition (b) output of the proposed controller at light-load condition.

"Fig. 5(a)" "Fig. 5(b)" shows the output of the dual mode controller at heavy load and light load conditions respectively. In heavy-load, the boost PFC converter is operated and the zero-current detector will be turned off immediately so that the controller will be operated in CCM. Therefore the input current is operated in continuous mode when the output load is in heavy load. As the output of the zero hysteresis comparator is maintained at a zero level, it disables the synchronous signal $\mathrm{V}_{\text {pulse }}$. On the contrary, the boost PFC is operated at critical conduction mode (CRM) when the output load is changed to light load. The signal $\mathrm{V}_{\text {pulse }}$ will be enabled so that the switching frequency of the boost PFC is changed.
The overall output for the proposed converter is shown as in "Fig. 6".

"Fig 6(a)" shows the control signals of the main and auxiliary switches. Both the main switch and auxiliary switch operates at $50 \mathrm{~Hz}$. The gate pulse to the main switch, $S_{1}$ and the auxiliary switch, $S_{2}$ are set based on the load current $I_{L}$. $S_{2}$ is the inverted waveform of $S_{1}$. $S_{1}$ and $S_{2}$ are switched $\mathrm{ON}$ and $\mathrm{OFF}$ at zero crossings. The voltage and current waveforms of the main switch, $\mathrm{S}_{1}$ is shown in 'Fig 6(b)". It can be seen that $\mathrm{S}_{1}$ is operated under SS for both turn $\mathrm{ON}$ and turn OFF processes. There are no overlap between voltage and current waveforms for the main switch, $\mathrm{S}_{1}$. There is no additional voltage stresses as shown in the voltage waveform.

"Fig 6(c)" shows the voltage and current waveforms of the auxiliary switch, $\mathrm{S}_{2}$. The auxiliary switch is turned $\mathrm{ON}$ and OFF under ZCS conditions. The voltage and current waveforms of the snubber capacitor is shown in 'Fig 6(d)". when $\mathrm{S}_{2}$ is turned $\mathrm{ON}$, the voltage across the snubber capacitor starts to increase and when the $\mathrm{S}_{2}$ is turned OFF, the voltage drops to zero."Fig 6(e)" and (f) exhibits the voltage and current of $\mathrm{L}_{\mathrm{R} 1}$ and $\mathrm{L}_{\mathrm{R} 2}$ respectively. The main diode voltage and current waveforms are shown in 'Fig $6(\mathrm{~g}) "$.
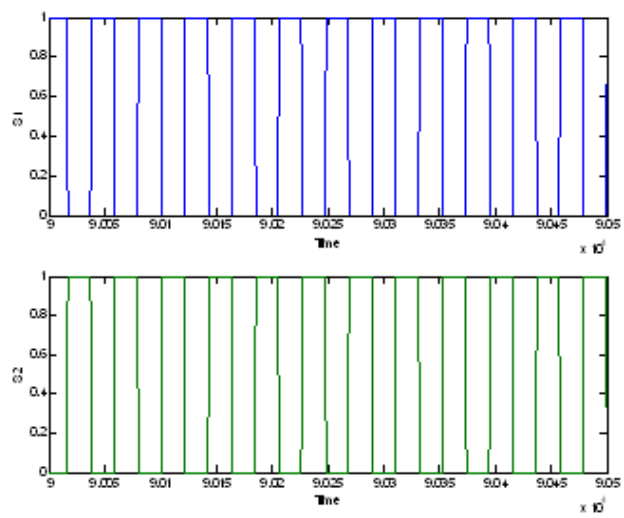

(a)
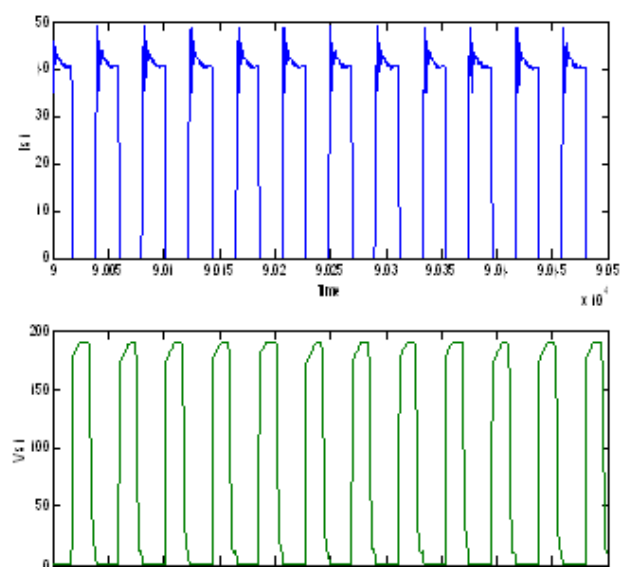

(b) 

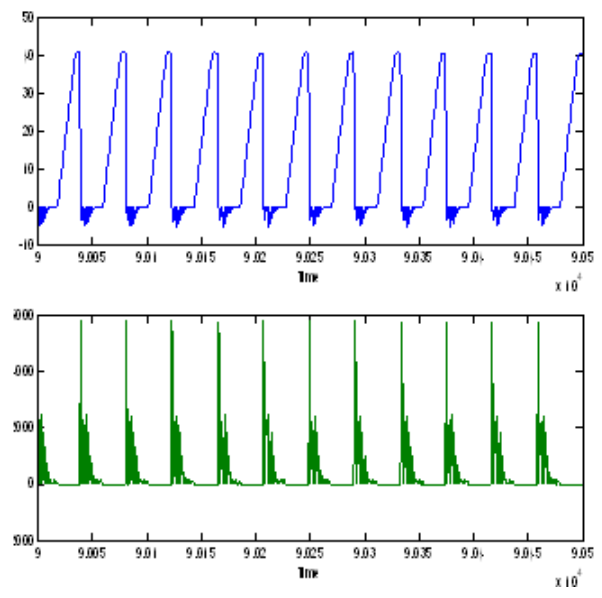

(c)
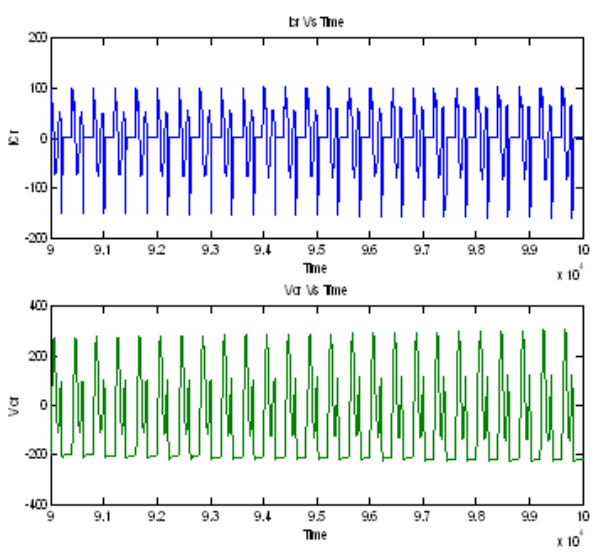

(d)

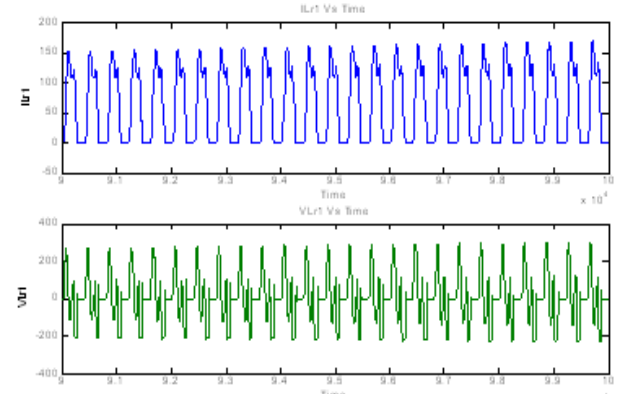

(e)
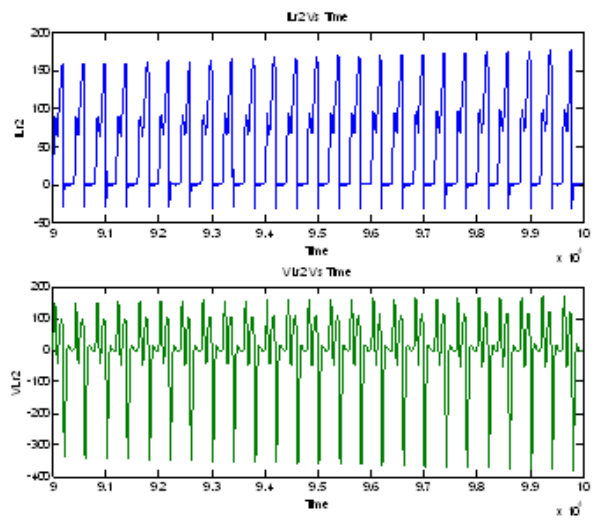

(f)

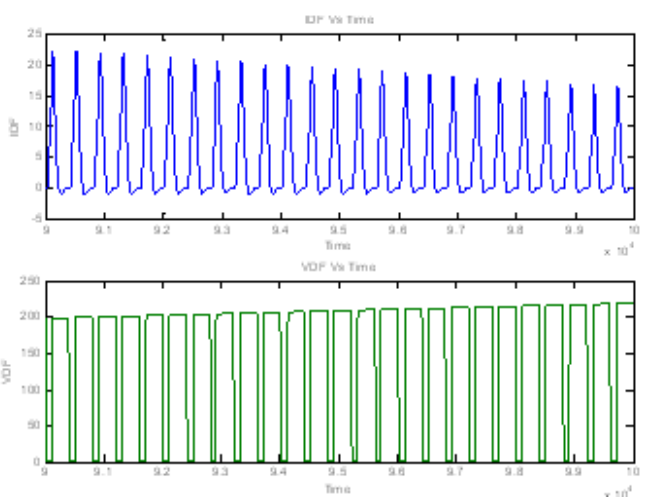

(g)

Figure 6. Waveforms of (a) Control signals of $S_{1}$ and $S_{2}$ (b) Voltage and current of main switch, $S_{1}$ (c) Voltage and current of auxiliary switch, $S_{2}(d)$ Voltage and current of snubber capacitor, $C_{R}(e)$ Voltage and current of snubber inductance, $L_{R I}(f)$ Voltage and current of snubber inductance, $L_{R 2}$ (g) Voltage and current of the main diode, $D_{F}$.

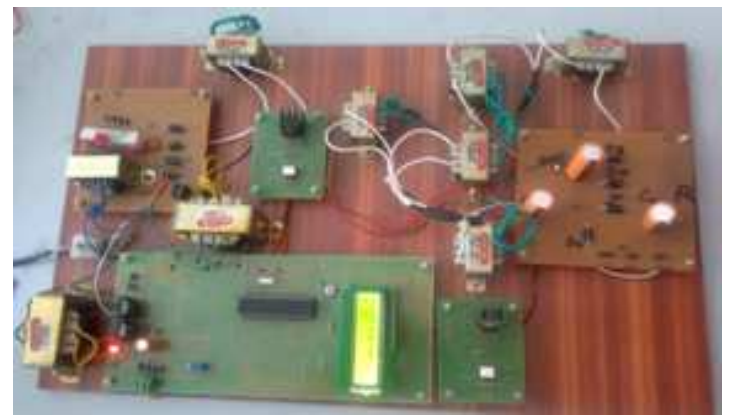

Figure 7. (a) Hardware Module

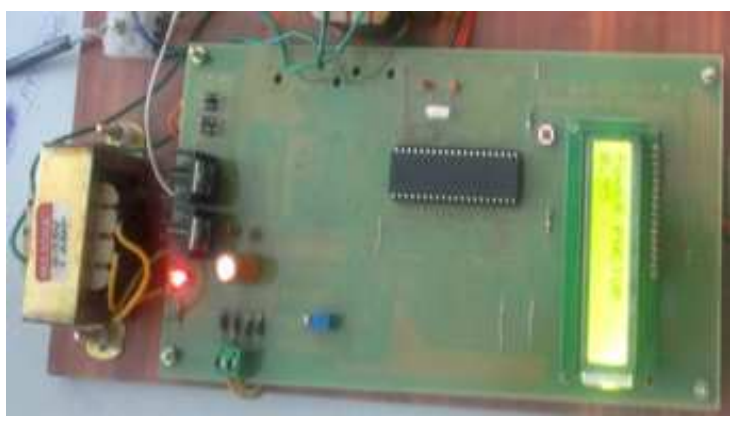

Figure 7. (b) Control Circuit

\subsection{Hardware Results}

The hardware module of the power factor correction converter implementing dual mode controller is shown in "Fig. 7. (a)". the hardware model consists of the following units. i.power supply unit ii.Power circuit iii.control circuit. Control circuit consists of MOSFET and IGBT are gate controlled devices, so they need gate pulses for their turn on. Here the gate pulse is provided by the microcontroller PIC 16F87XA shown in "Fig. 7. (b)". The control circuit also consists of a $230 \mathrm{~V}$ single phase diode bridge rectifier, voltage regulator, capacitor and a liquid crystal display. 


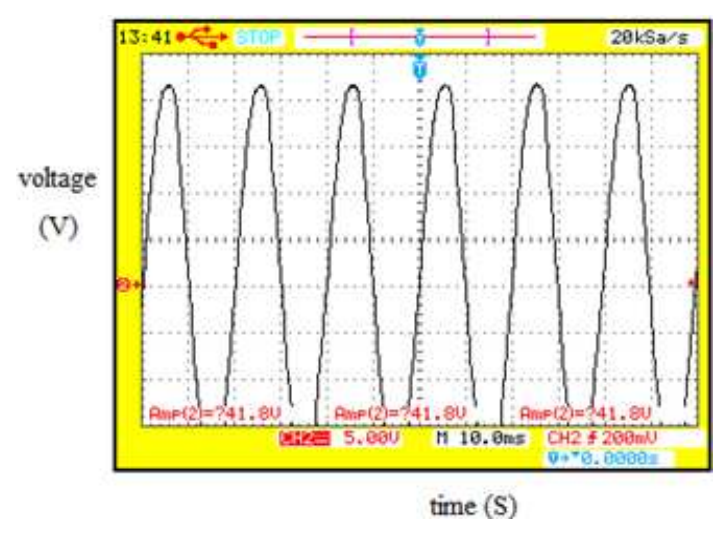

Figure 7. (c)Input Voltage

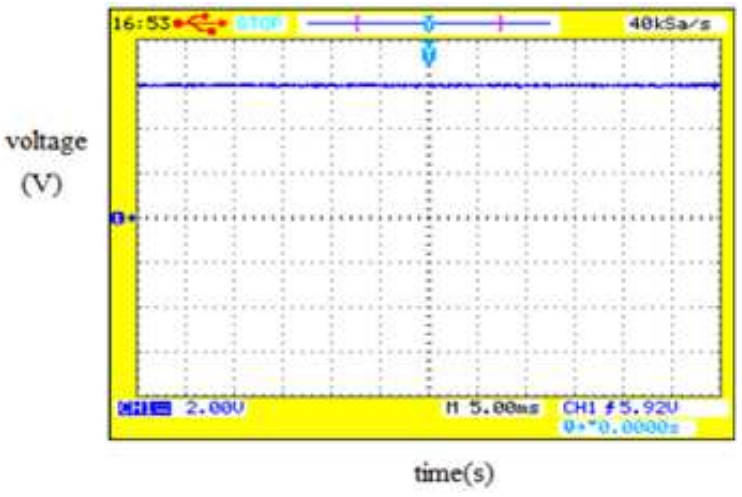

Figure 7. (d) Output Voltage

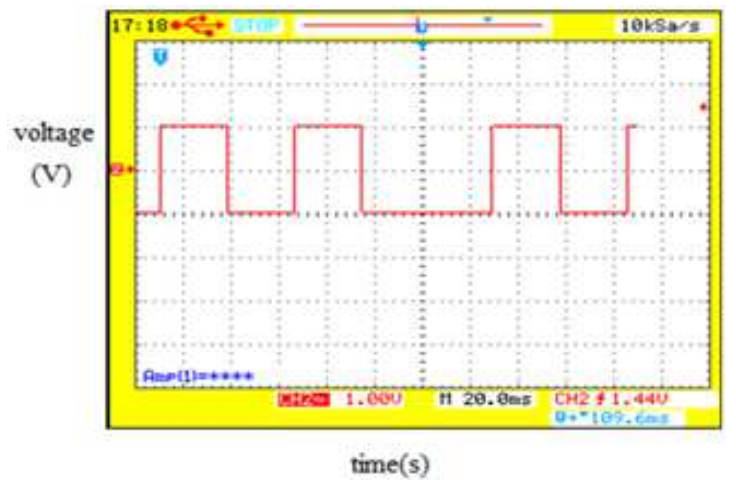

Figure 7. (e)Gate Pulse to the Main Switch, S1

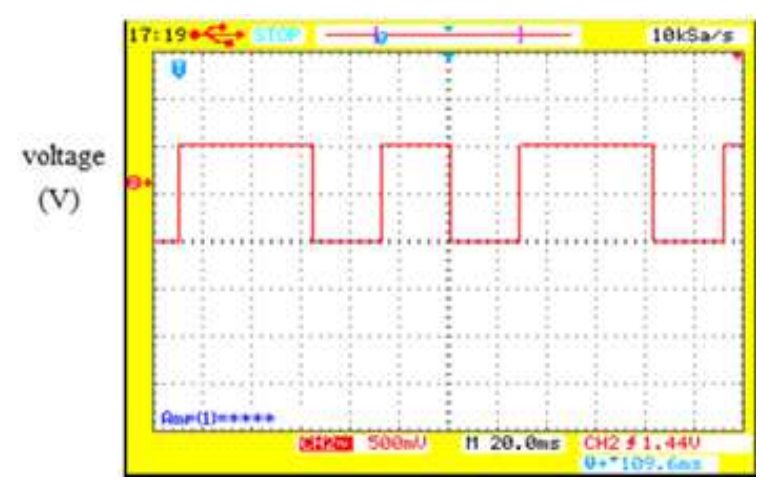

Figure 7. (f) Gate Pulse to the Auxillary Switch, S2

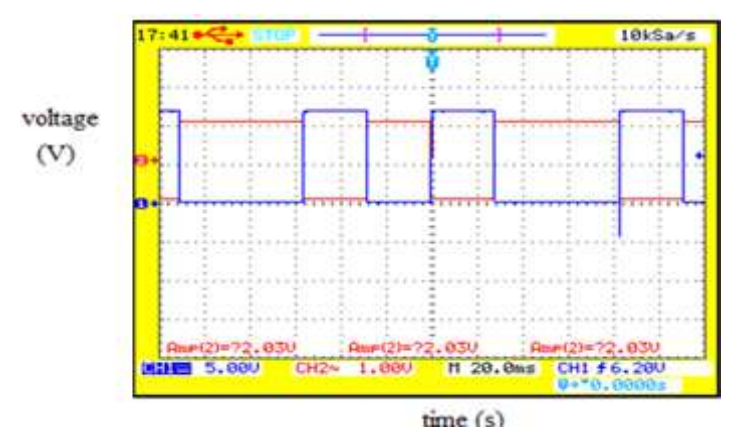

Figure 7. (g) Gate Pulses to S1and S2 showing they are inverted

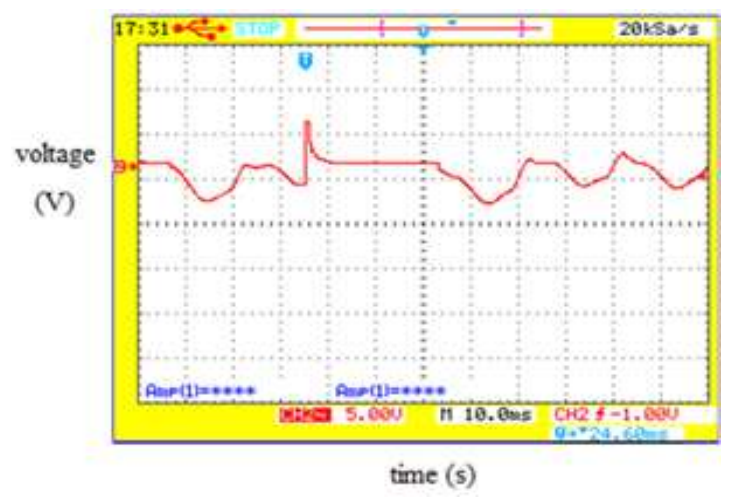

Figure 7. (g) Output of the Snubber Capacitor, CR

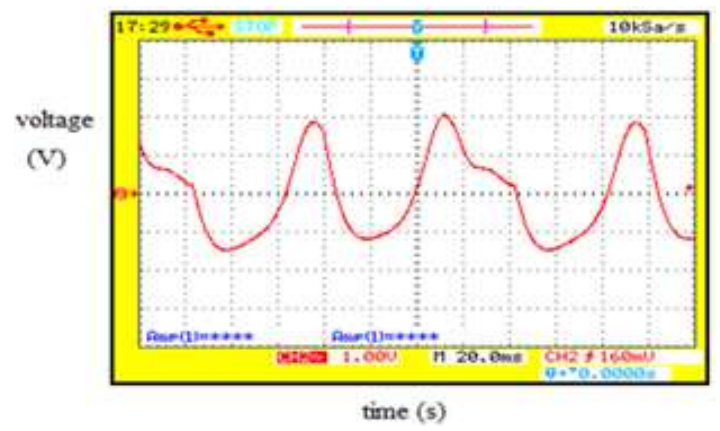

Figure 7. (h) Output of the Snubber Inductance, LR1

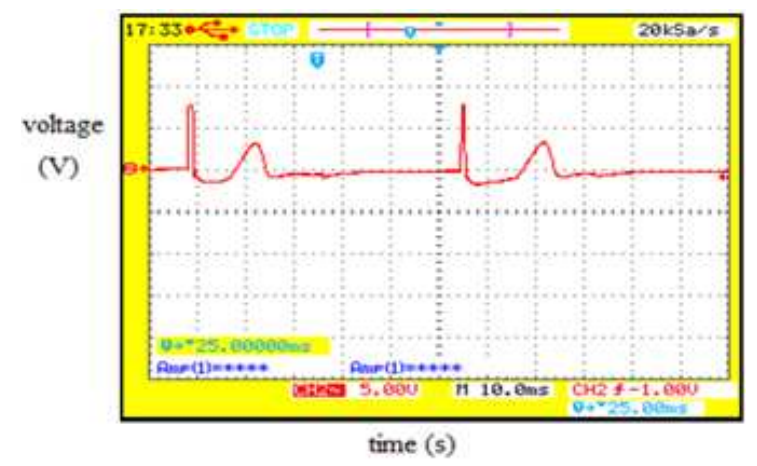

Figure 7. (i) Output of the Snubber Inductance, LR2

The comparison of power factor for the existing and proposed system is explained as in"Fig. 8". The main problem in the existing system is at the light load conditions. At 25W (light-load condition) load, the existing system has a power factor of about 0.92 but this value is increased in the proposed system by 0.97 . At $75 \mathrm{~W}$ the 
power factor of the existing system is 0.96 and it is increased above 0.98 in the proposed system. At $150 \mathrm{~W}$ (medium-load condition), the power factor of 0.97 in the existing system is increased to 0.99 in the proposed system. At 300W (high-load condition), both the existing and proposed systems have almost the same power factor, i.e., approximately equal to unity. In short, at no load the power factor of $92 \%$ in the existing system is increased to above $96 \%$ in the proposed system and at full load, the power factor is almost the same in both the cases. So the problem of low power factor at light load is resolved in the proposed system using a dual mode controller.

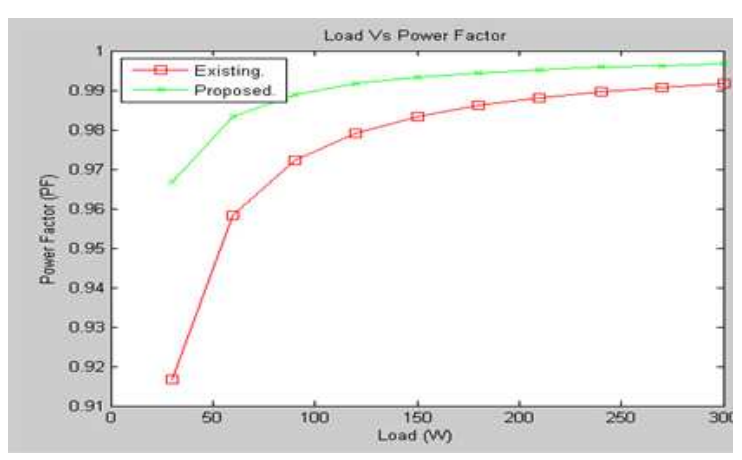

Figure 8. PF plot-existing versus proposed scheme

\section{Conclusion}

This paper presents a single phase power factor correction converter implementing an active snubber circuit and a dual mode controller. This new PFC is realized with a $200 \mathrm{~V}$ ac input to provide a $400 \mathrm{~V}$ dc output. This PFC consists of a main switch that is turned ON by ZVT and turned OFF by ZCT and an auxiliary switch that has ZCS turn $\mathrm{ON}$ and turn OFF. The active snubbercircuit provide soft switching to the main and auxiliary switches, thus eliminating the voltage and current stresses on the main switch. The voltage stresses on the auxiliary switch is also eliminated, but the current stresses exists which can be reduced by transferring these stresses to the output load by coupling inductance. The dual mode control method combines both CCM and CRM and it provides high power and efficiency at light-load conditions. The dual-mode controller of the boost PFC is particularly suitable for a fixed frequency boost PFC controller the dual mode control circuit is simple and easy to implement in the IC without much additional space and cost. The overall efficiency and optimum power factor is obtained at both light-load and heavy-load conditions.

\section{References}

[1] G. Seguier, Power Electronic Converters AC/DC conversion. New York: McGraw Hill, 1986.
[2] E. Masek, E. Dede, G. Hua and F.C. Lee, "100 KHz $2 \mathrm{~kW}$ boost ZVT-PWM converter for power-factor correction," in Pro. IEEE CIEP'93, pp. 102-106, 1993.

[3] J. W. Kim, S. M. Choi, and K. T. Kim, "Variable on-time control of the critical conduction mode boost power factor correction converter to improve zero-crossing detection", in Proc. IEEEPEDS, Nov. 2005, pp. 1542-1546.

[4] R. L. Lin, Y. Zhao, F.C. Lee, "Improved soft-switching ZVT converters with active snubber," in Appl. Power Electron. Conf. Exposition IEEE, vol.2, pp.1063-1069, Feb. 1998.

[5] Elasser and D.A. Torrey, "Soft switching active snubbers for dc/dc converters,'IEEE Trans. Power Electron., vol. 11, pp. 710-722, Sept. 1996.

[6] BurakAkin and HaziBodur, "A new single-phase soft-switching power factor correction converter," IEEE Trans. Power Electron., vol.26, no.2, pp.436-443, Feb. 2011.

[7] C. M. Wang, "A novel zero-voltage switching PWM boost rectifier with high power factor and low conduction losses," IEEE Trans. Ind. Electron., vol.52, no.2, pp.427-435, Apr. 2005.

[8] E. H. Ismail, A. J. Sabzali and M. A. Al-Saffar, "A high-quality rectifier based on Sheppard-Taylor converter operating in discontinuous capacitor voltage mode," IEEE Trans. Ind. Electron., vol.55, no.1, pp.38-48, Jan. 2008.

[9] E. Martinez and P.N Enjeti, "A high-performance single-phase rectifier with input power factor correction," IEEE Trans. Power Electron., vol.11, pp.311-317, July. 1996.

[10] H. Bodur and A.F. Bakan, "A new ZVT-ZCT-PWM DC-DC converter," IEEE Trans. Power Electron., vol.19, no.3, pp.676-684, Jan 2002.

[11] J. G. Cho, J. W. Baek, G. H. Ron, I. Kang, "Novel zero voltage transition PWM multiphase converters," IEEE Trans. Power Electron., vol.13, pp.152-159, Jan. 1998.

[12] R. T. H. Li, H.S.H. Chang and A.K.T Sing, "Passive lossless snubber for boost PFC with minimum voltage and current stress," IEEE Trans. Power Electron., vol.25, no.3, pp.602-613, Mar. 2010.

[13] S. Wall and R. Jackson, "Fast controller design for single-phase power-factor correction systems," IEEE Trans. Ind. Electron., vol.44, no.5, pp.654-660, Oct. 19997.

[14] T.C. Chen and C.T. Pan, "Modeling and design of a single-phase ac to dc converters," Proc. Inst. Elect., vol.136, pp. 465-470, Sept. 1992.

[15] V. Vorperian, "Quasi-square wave converters: Topologies and analysis." IEEE Trans. Power Electron., vol.3, no.2, pp. 183-191, Apr.1988.

[16] Y. Jang, M.M. Jovanovic, K.H. Fang and Y.M. Chang, "High-power-factor soft-switched boost converter" IEEE Trans. Power Electron., vol.21, no.1, pp.98-104, Jan. 2001. 